\title{
A Study on Sustainable Usage Intention of Blockchain in the Big Data Era: Logistics and Supply Chain Management Companies
}

\author{
Kwang O. Park \\ Division of Business, Yeungnam University College, 170 Hyeonchung-ro, Nam-gu, Daegu 42415, Korea; \\ kopark1021@ync.ac.kr; Tel.: +82-53-650-9333; Fax: +82-53-625-6246
}

Received: 13 November 2020; Accepted: 17 December 2020; Published: 21 December 2020

\begin{abstract}
The adoption of blockchain technology (BT) is becoming increasingly important to the logistics industry. It is expected to make the entire supply chain process more efficient and competitive by providing visibility, reliability, and economic viability. This study aims to explore factors influencing the adoption of blockchain in the logistics industry and examine the effects of the reciprocal causal relationship between the identified factors. Empirical research aimed at understanding the functional characteristics of BT and bolstering its application is considerably lacking. This study, therefore, aims to examine the concepts and the types of BT based on a literature review related to blockchain. Factors affecting blockchain adoption are identified using a model, which was developed using the unified theory of acceptance and use of technology (UTAUT) and the technology-organization-environment (TOE) frameworks as well as a literature review. The results provide fundamental insights into the adoption of $\mathrm{BT}$ in the logistics industry by increasing the understanding of associated factors and underscoring the functional characteristics of this emerging technology.
\end{abstract}

Keywords: sustainable usage intention; blockchain; UTAUT; TOE; supply chain management (SCM); logistics

\section{Introduction}

Blockchain technology (BT) is regarded as one of the key underlying technologies that will drive the fourth industrial revolution. Many experts in related fields predict that when blockchain initiatives are commercialized, their features will serve as a platform that is applicable across industries, including finance [1].

Specifically, BT provides opportunities for new methods of concurrently transferring digital values and information, promoting digitization and convergence across all industries, including finance, manufacturing, distribution, and public sectors. In this context, knowledge about the adoption of new technologies becomes more important in creating value, particularly in the logistics industry [2].

Blocks in the blockchain store transactional data, which are encrypted into a series of numbers and letters while being joined together in chronological order. BT made its debut in 2008 with the introduction of Bitcoin, which was invented by a person using the name Satoshi Nakamoto.

Blockchain-based technologies are characterized by their security, transparency, speed, P2P-based features, viability, availability, reliability, versatility, scalability, safety, and the lack of a need for intermediaries [3]. Given these benefits and features, BT is rapidly evolving in the finance and the logistics industries [4].

Fintech and IT companies invest in and cooperate with each other to develop a variety of blockchain platforms in the banking and the finance sectors. The e-commerce industry is also pursuing a path to blockchain commercialization to allow secure peer-to-peer transactions [1]. 
The logistics industry is primed for the adoption of BT. The application of BT in logistics operations is expected to improve efficiency and competitiveness in the supply chain ecosystem by providing visibility, reliability, and economic viability. Based on this, the adoption of BT seems imperative for logistics companies, with calls for an industry-wide effort to achieve that [5].

As such, BT has high application prospects in logistics services. To the best of our knowledge, the logistics industry has the second highest application potential after the banking and the financial sectors when it comes to BT. We, therefore, decided to focus on logistics companies in this study. Furthermore, this study aims to explore the factors that influence the intention to adopt BT. Among the models established to explain the adoption of technology are the unified theory of acceptance and use of technology (UTAUT) model and the technology-organization-environment (TOE) frameworks.

The UTAUT is one of the most common models used to explain how companies or individuals come to accept and use a new technology when it is available [6]. In addition, this study used the TOE framework to identify the factors that are associated with the intention to adopt BT. These theoretical frameworks are considered appropriate for studying early adoption of BT, as the logistics industry needs innovation.

Furthermore, this study examines the effect of the reciprocal causal relationship among the factors identified based on the intention to adopt BT. Previous research has focused on studying and analyzing the trends in BT, application cases, and legal and policy requirements for blockchain adoption. Hence, empirical research aimed at understanding the functional characteristics of BT and bolstering its application is considerably lacking. This study, therefore, addresses this concept and the types of BT based on a literature review, discussing BT application cases, particularly in the logistics industry. A conceptual research model is illustrated in Figure 1.

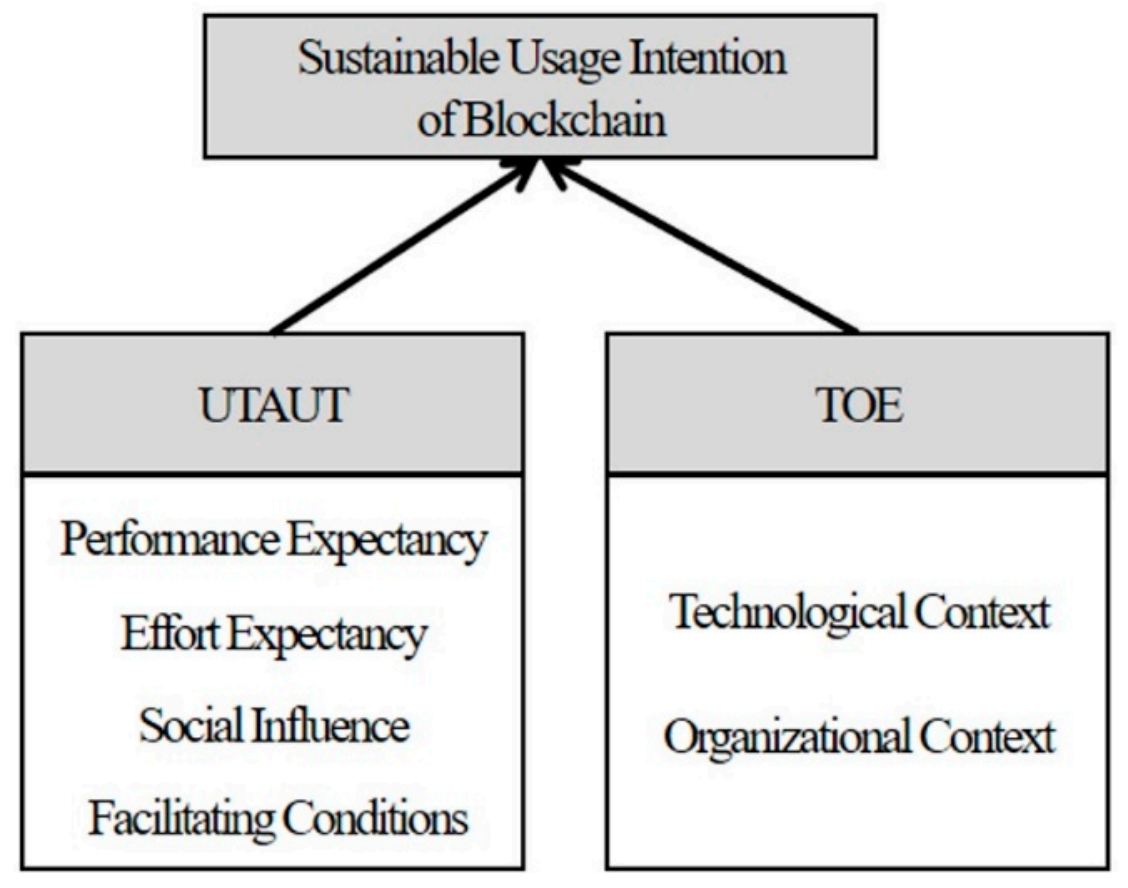

Figure 1. Conceptual research model.

Survey data were collected from experts in the logistics field using a questionnaire, in which survey variables were operationally defined. Collected data were empirically analyzed using SPSS 24.0 and AMOS 24.0. The results provide the fundamental information necessary for the adoption of BT in logistics contexts by increasing the understanding of the associated factors and underlining features of this emerging technology. 


\section{Theoretical Background}

\subsection{Concept and Types of Blockchain}

Blockchain can be defined according to various application-specific elements, such as industrial nature, technology level, and supply chain process [3]. As a type of distribution database, blockchain is a continuously growing list of data records [4].

BT can be applied in all areas, such as finance, logistics, and public sectors, and can enhance safety and efficiency. In October 2008, Satoshi Nakamoto introduced Bitcoin as a peer-to-peer electronic currency. BT, which was developed in an open source manner, is evolving into private blockchains with improved scalability and efficiency and is expected to be used as SOC in the future [1].

The functional characteristics of blockchain vary based on participants (nodes), suppliers, and authority and role of administrators in the network. Based on the presence or the absence of a transaction validation mechanism, blockchain networks are classified as public blockchain, consortium blockchain, or private blockchain [5].

As the first version of blockchain networks, public blockchain networks are not expandable, and consensus is managed by all participants in transactions. Their advantages include their security, reliability, anonymity, and transparency. However, they are far less scalable and have slow transaction speeds.

Consortium blockchain networks are semi-centralized and easy to expand, and consensus is managed by a set of participants of the consortium. They are highly efficient and scalable, with high transaction speeds and the ability to assign sensitive data processing tasks. Their disadvantages are that human intervention may be required to process transactions, and they have low transparency and security.

Private blockchain networks are peer-to-peer networks built on a platform, where consensus is managed by a single centralized institution. They are characterized by high efficiency and scalability, with the ability to process more transactions per second and to adapt to the characteristics of businesses. However, their security level is low.

\subsection{Blockchain Logistics Applications}

$\mathrm{BT}$ is creating a more reliable and transparent logistics flow by providing data immutability, which does not allow any retroactive alteration, manipulation, or hacking attempts [7].

While the global supply chain has been expanded and its complexity has increased, bottlenecks have become apparent in the fields of logistics (delivery, forwarding, import and export, etc.) and international trade [8]. Accordingly, global logistics visibility is emerging as an indispensable solution for improving the competitiveness of the logistics industry around the world. Hence, BT is considered to be a new secure form of transaction recording, which has great potential for a broad range of applications, including distribution, shipping logistics, and global supply chains, in addition to finance transactions $[9,10]$.

In 2017, the Musk Group decided to develop a BT-based shipment tracking solution in collaboration with IBM. Such a tracking system was expected to enable real-time tracking of the movements of more than 10 million shipping containers floating around the globe. In addition to the transfer of assets, such as cargo being shipped, all transaction records made within the supply chain would be traceable as part of the traceability improvement process [11].

Thus, integration attempts have been made with BT in the logistics field, even though the expected outcomes have not yet materialized [6,12]. Blockchain is a must-have technology for the logistics industry. Therefore, we review the literature on the functional characteristics of blockchain to develop a research model and hypotheses. We also address the UTAUT and the TOE frameworks in order to utilize them for the research model, with the aim of identifying factors affecting the adoption of BT. Specifically, based on the literature review on UTAUT and TOE application cases, we establish a theoretical rationale and a novel approach for this study. 


\subsection{UTAUT}

The UTAUT model is an information system (IS) theory used to analyze the intentions and the behavior of users. It combines the models of the theory of reasoned action (TRA), the theory of planned behavior (TPB), the technology acceptance model (TAM), the motivation model (MM), the model of PC utilization (MPCU), the innovation diffusion theory (IDT), and the social cognitive theory (SCT) [13]. As shown in Figure 2, the UTAUT model consists of four main constructs that predict the intention to adopt an IS-performance expectancy, effort expectancy, social influence, and facilitating conditions. While the technology acceptance model (TAM) was proven to have about $40 \%$ of the explanatory power, when its validity was tested in the business sector, including for logistics [2] and supply chain management (SCM) [14], the UTAUT model's explanatory power improved to about 70\%, in addition to providing multiple predictors [13]. Thus, the UTAUT is more widely used when validating the intention to adopt logistics systems, application programs (e.g., SCM), and new information technologies [15,16].

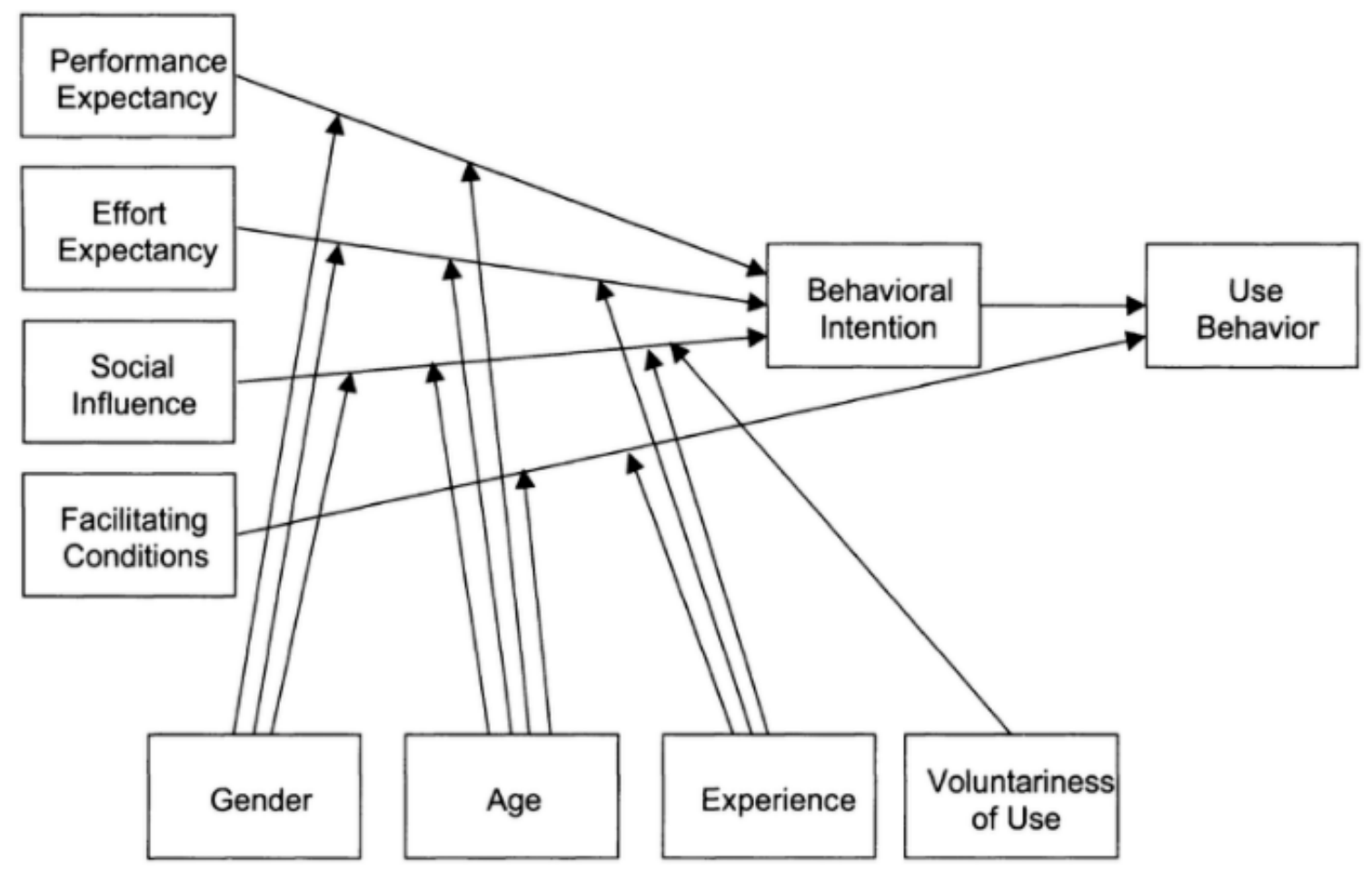

Figure 2. Unified theory of acceptance and use of technology (UTAUT) model.

Performance expectancy is defined as the degree to which an individual believes that using the technology will help them attain the level of work performance expected. Effort expectancy refers to the degree of ease associated with the use of technology. Social influence is the extent to which an individual feels that others believe they should use a new technology. Facilitating conditions is the degree to which organizational and technical infrastructure exists to support the use of new technologies.

\subsection{TOE Framework}

As shown in Figure 3, Tornatzky et al. (1990) [17] proposed the TOE framework to analyze the factors influencing the selection and adoption of innovative information technology.

The TOE model has been widely used by enterprises as an appropriate framework when analyzing the adoption of new technologies. It explains factors that influence the process by which a firm adopts information technology based on three constructs-technological context, organizational context, and external task environmental context [18]. 


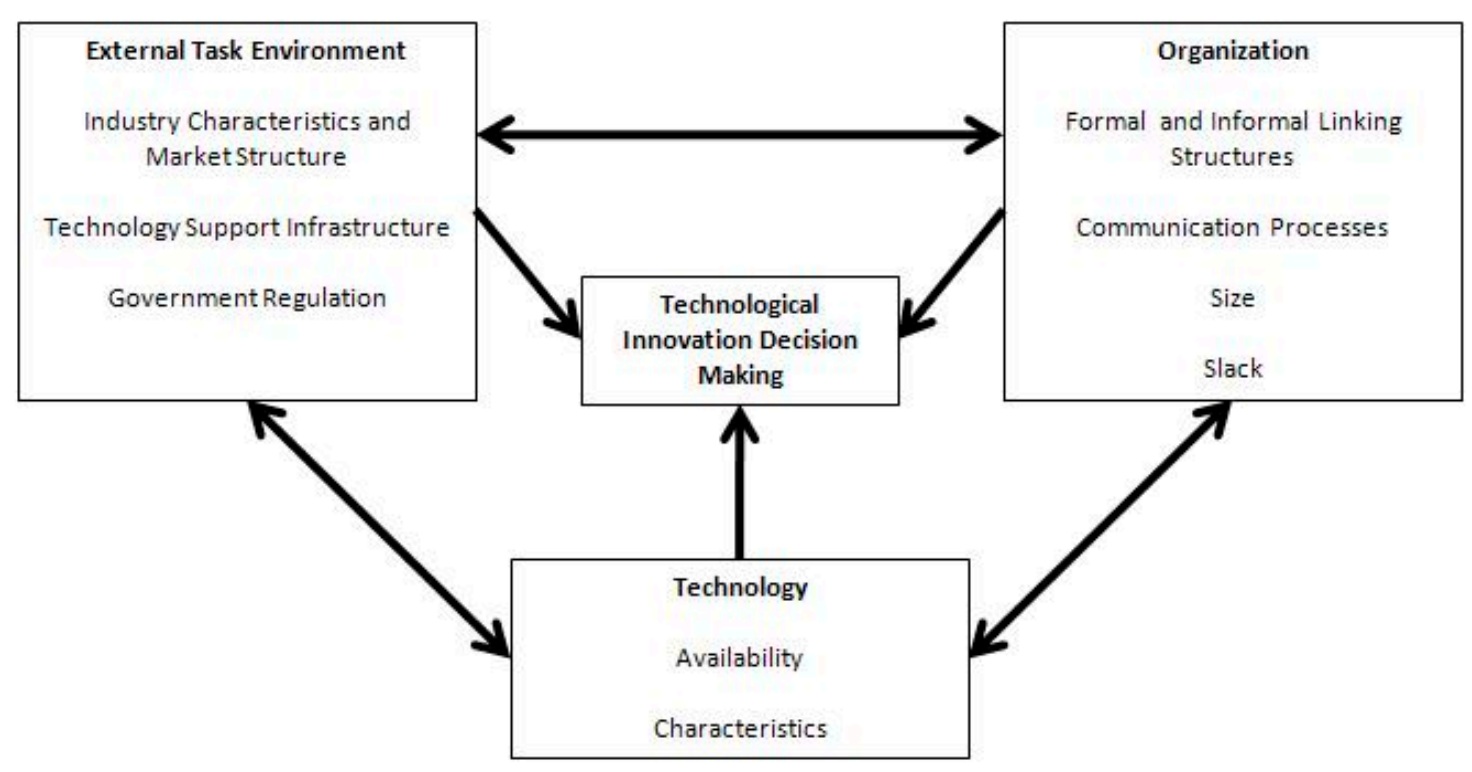

Figure 3. Technology-organization-environment (TOE) framework.

The technological context includes internal and external technologies that are relevant to the adoption of innovation within the firm. The organizational context includes quality of human resources, complexity of managerial structure, degree of centralization, degree of formalization, and firm's size and scope. The external task environmental context includes industry concerned, firm's competitors, government policy, and regulatory environment $[19,20]$.

The following studies explained the adoption of blockchain using the TOE framework. Crosby (2016) [21] and Wang (2016) [22] identified technological, organizational, and environmental factors influencing the adoption of blockchain within the TOE framework [23]. Chen (2015) [24] analyzed the effects of technological, organizational, and environmental factors on the intention to adopt information system using the TOE framework.

This study focuses on the technological and the organizational contexts among TOE constructs and integrates this with the UTAUT model, excluding the "external task environmental context."

\section{Research Model and Hypotheses}

This study aims to explore factors influencing the adoption of blockchain in the logistics industry using the UTAUT and the TOE frameworks and to examine the effects of the reciprocal causal relationship between the factors identified with the intention to adopt BT. Therefore, this study proposes a conceptual research model of factors affecting BT adoption, as illustrated in Figure 4, and the hypotheses formulated are empirically tested using structural equation modeling (SEM).

\subsection{Hypotheses Development}

Many studies have identified UTAUT constructs as factors that positively affect the attitude and the sustainable usage intention of information system [2]. Hence, UTAUT constructs as independent variables have strong explanatory power over the dependent variable.

We consider UTAUT constructs to be the most important factors affecting the sustainable usage intention of IS, based on studies exploring factors associated with the intention to adopt new technology [14]. Combined, these findings suggest a hypothesis that UTAUT constructs will affect attitude and sustainable usage intention.

Hypothesis 1 (H1). UTAUT constructs will influence attitude towards blockchain.

Hypothesis 2 (H2). UTAUT constructs will influence the sustainable usage intention of blockchain. 
Successful adoption of new technology is largely influenced by an organization's technological capability, albeit to varying degrees [18]. Additionally, the adoption and the implementation of new technology requires organizational support, backed up by technical infrastructure. In the presence of consistent organizational support, the intention to adopt innovation will increase [19]. The underlying factors are related to infrastructure, such as the perceived need for and interest in new technology and adequate manpower.

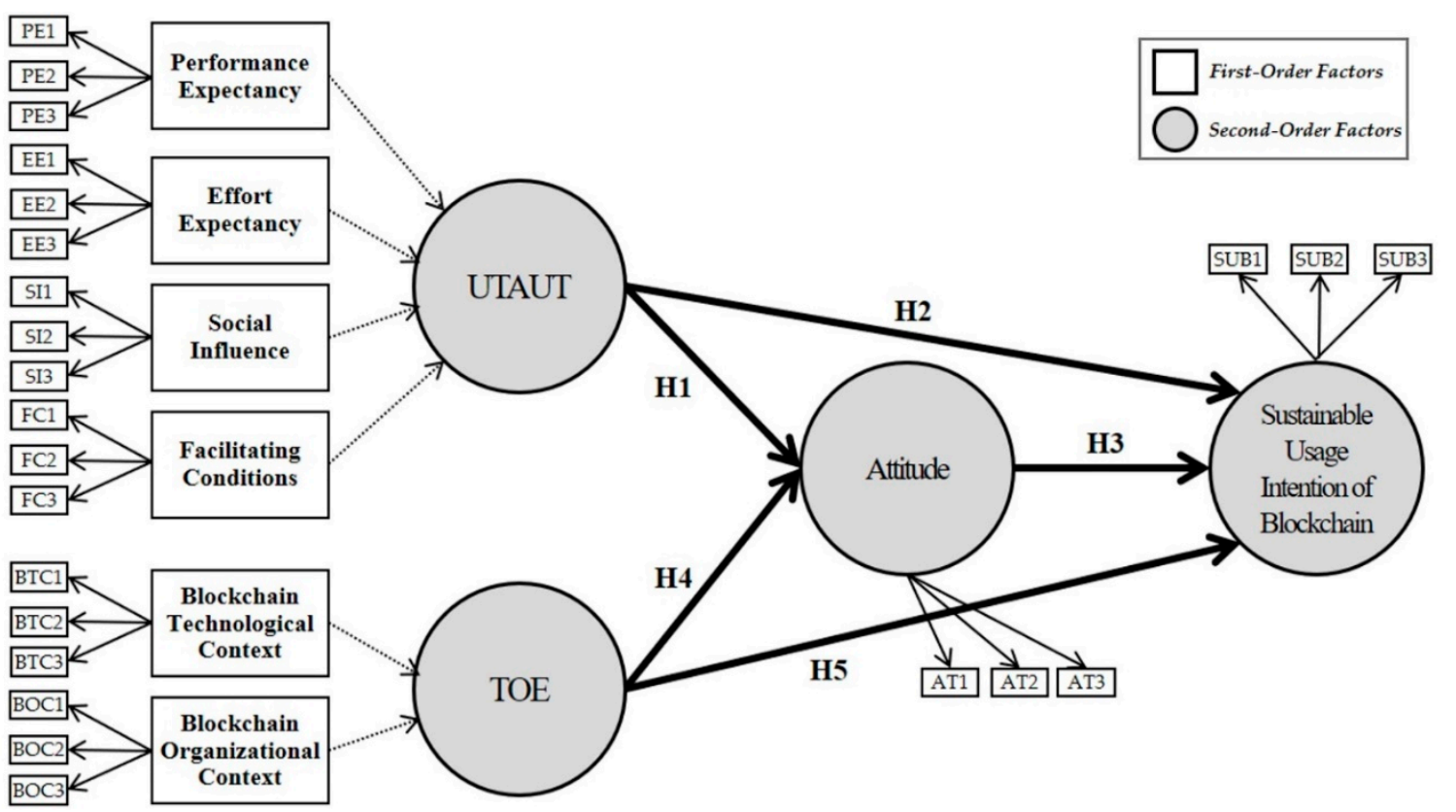

PE : Performance Expectancy, EE : Effort Expectancy, SI :Social Influence

FC : Facilitating Conditions, BTC : Blockchain Technological Context

BOC : Blockchain Organizational Context, AT: Attitude, SUB: Sustainable Usage Intention of Blockchain

H1: Hypothesis 1; H2: Hypothesis 2; H3: Hypothesis 3; H4: Hypothesis 4; H5: Hypothesis 5

Figure 4. Research model.

Users' interest and opinions regarding the adoption of new technology are also important due to possible post-adoption changes, which include internal transfers, change to tasks, and excessive burden of learning [23]. Based on these data, a hypothesis was developed: TOE constructs (technological and organizational contexts) will affect the attitude towards and the sustainable usage intention of blockchain.

Hypothesis (H3). TOE constructs will influence attitude towards blockchain.

Hypothesis (H4). TOE constructs will influence the sustainable usage intention of blockchain.

Many studies have suggested a positive attitude as an antecedent in the relationship with the use intention. Attitude is considered as an important factor exerting a positive influence on the intention to adopt new technology and customer services [13]. Many studies have described attitude as a positive antecedent of the use intention [14]. Based on the above discussion, a hypothesis is established that attitude will affect the use intention.

Hypothesis 5 (H5). Attitude will affect use behavior. 


\subsection{Data Collection and Methodology}

As shown in Table 1, each research construct was measured using survey questions developed based on a literature review.

Table 1. Research constructs and operationalization.

\begin{tabular}{|c|c|c|}
\hline Construct & Items & References \\
\hline \multirow{3}{*}{ Performance Expectancy } & $\begin{array}{l}\text { Blockchain will facilitate the use of a } \\
\text { variety of information. }\end{array}$ & \multirow{12}{*}{$\begin{array}{c}\text { Zakky and Teguh (2018) [2] } \\
\text { Venkatesh et al. (2003) [13] } \\
\text { Queiroz et al. (2020) [14] } \\
\text { Chan et al. (2012) [15] } \\
\text { Dulle and Minishi-Majanja (2011) [16] }\end{array}$} \\
\hline & $\begin{array}{l}\text { Blockchain will provide information } \\
\text { useful for decision making. }\end{array}$ & \\
\hline & $\begin{array}{l}\text { Blockchain will help improve } \\
\text { management performance. }\end{array}$ & \\
\hline \multirow{3}{*}{ Effort Expectancy } & I will try to adopt (implement) blockchain. & \\
\hline & $\begin{array}{l}\text { I will learn to adopt } \\
\text { (implement) blockchain. }\end{array}$ & \\
\hline & $\begin{array}{l}\text { I will be trained to adopt } \\
\text { (implement) blockchain. }\end{array}$ & \\
\hline \multirow{3}{*}{ Social Influence } & Blockchain has good social effects. & \\
\hline & $\begin{array}{l}\text { Blockchain adoption is recommended } \\
\text { by others. }\end{array}$ & \\
\hline & $\begin{array}{l}\text { The use of blockchain becomes } \\
\text { increasingly apparent in the social context. }\end{array}$ & \\
\hline \multirow{3}{*}{ Facilitating Conditions } & $\begin{array}{l}\text { We have the knowledge necessary to } \\
\text { adopt blockchain. }\end{array}$ & \\
\hline & $\begin{array}{l}\text { We have the resources necessary to } \\
\text { implement blockchain. }\end{array}$ & \\
\hline & We are ready to implement blockchain. & \\
\hline \multirow{3}{*}{$\begin{array}{l}\text { Blockchain Technological } \\
\text { Context }\end{array}$} & $\begin{array}{l}\text { We have the technological environment } \\
\text { suitable for blockchain. }\end{array}$ & \multirow{6}{*}{$\begin{array}{c}\text { Tornatzky et al. (1990) [17] } \\
\text { Chan and Chong (2013) [18] } \\
\text { Lian et al. (2014) [19] } \\
\text { Oliveira et al. (2014) [20] } \\
\text { Crosby et al. (2016) [21] } \\
\text { Wang et al. (2016) [22] } \\
\text { Sun et al. (2018) [23] } \\
\text { Chen et al. (2015) [24] }\end{array}$} \\
\hline & $\begin{array}{l}\text { We are capable of } \\
\text { implementing blockchain. }\end{array}$ & \\
\hline & We are able to learn blockchain. & \\
\hline \multirow{3}{*}{$\begin{array}{l}\text { Blockchain Organizational } \\
\text { Context }\end{array}$} & $\begin{array}{l}\text { The management is interested in adopting } \\
\text { blockchain. }\end{array}$ & \\
\hline & $\begin{array}{l}\text { The management perceives that } \\
\text { blockchain is necessary. }\end{array}$ & \\
\hline & $\begin{array}{l}\text { We have appropriate human resources to } \\
\text { adopt (implement) blockchain. }\end{array}$ & \\
\hline \multirow{3}{*}{ Attitude } & $\begin{array}{l}\text { I agree with the adoption } \\
\text { (implementation) of blockchain. }\end{array}$ & \multirow{3}{*}{$\begin{array}{l}\text { Zakky and Teguh (2018) [2] } \\
\text { Chan and Chong (2013) [18] } \\
\text { Lian et al. (2014) [19] }\end{array}$} \\
\hline & $\begin{array}{l}\text { I will accept any changes resulting from } \\
\text { blockchain adoption (implementation). }\end{array}$ & \\
\hline & $\begin{array}{l}\text { I will actively participate in the adoption } \\
\text { (implementation) of blockchain. }\end{array}$ & \\
\hline \multirow{3}{*}{$\begin{array}{l}\text { Sustainable Usage } \\
\text { Intention of Blockchain }\end{array}$} & I am willing to adopt blockchain. & \multirow{3}{*}{$\begin{array}{l}\text { Venkatesh et al. (2003) [13] } \\
\text { Queiroz et al. (2020) [14] } \\
\text { Sun et al. (2018) [23] }\end{array}$} \\
\hline & $\begin{array}{l}\text { I am continuously looking for } \\
\text { blockchain-based tasks. }\end{array}$ & \\
\hline & $\begin{array}{l}\text { I like to utilize blockchain for } \\
\text { multiple purposes. }\end{array}$ & \\
\hline
\end{tabular}

A total of 800 questionnaires were used for empirical analysis, and $177(22.1 \%)$ were collected. After the exclusion of incomplete questionnaires, the remaining 172 (21.5\%) questionnaires were used for analysis. 
According to the demographic profile, the numbers of male and female respondents were 151 $(88 \%)$ and $21(12 \%)$, respectively. By age, those in their 40s constituted the largest group $(n=85,49 \%)$, followed by the 30s age group $(n=70,41 \%)$ and the 50 s or above age group $(n=17,10 \%)$.

By job title, managers made up the largest group $(n=74,43 \%)$, followed by assistant managers $(n=19,11 \%)$, general managers $(n=68,39 \%)$, and executive directors $(n=11,7 \%)$.

As managers with more than 10 years of experience constituted the largest portion of the sample $(89 \%)$, the sampling is considered appropriate for this study, which was designed to explore the intention to adopt blockchain in logistics operations. In addition, the study population was suitable for investigating the intention to adopt BT, because the largest number of respondents $(n=158,92 \%)$ were working in logistics and distribution settings, followed by other industries ( $n=14,8 \%)$. Hence, the results of this study can be generalized. The profiles of respondents and their companies are outlined in Table 2 below.

Table 2. Profiles of companies and respondents.

\begin{tabular}{ccc}
\hline & Frequency & Percent (\%) \\
\hline Gender of respondent & & \\
\hline Male & 151 & 88 \\
Female & 21 & 12 \\
\hline Age of respondent & & \\
\hline $30-40$ & 70 & 41 \\
$40-50$ & 85 & 49 \\
Over 50 & 17 & 10 \\
\hline Title of respondent & & \\
\hline Assistant manager & 19 & 11 \\
Manager & 74 & 43 \\
General manager & 68 & 39 \\
Executive director & 11 & 7 \\
\hline Type of Industry & & \\
\hline Other Industry & 158 & 92 \\
\hline
\end{tabular}

Confirmatory factor analysis (CFA) was performed to test the validity of the constructs. Factors that have eigenvalues $\geq 1$ were chosen, and extracted factors were rotated by varimax rotation for analysis. An adequate sample size is required to achieve a specific level of significance. For a sample size of more than 100, factor loadings values ranging from 0.50 to 0.55 are considered significant. As the sample size was 172 , factors loadings of at least 0.5 were chosen in this study. As presented in Table 3 , the CFA results revealed that all factor loadings exceeded the cut-off value, confirming the validity of the measured variables [25].

In addition, this study used the second-order construct in the research model to measure whether the UTAUT model consisted of performance expectancy, effort expectancy, social influence, and facilitating conditions and whether the TOE framework comprised technological and organizational contexts. Therefore, the convergent and the discriminant validity were examined to assess the validity of the model. Convergent validity refers to the degree of correlation between at least two measurement scales used to measure the same construct and relies on the construct reliability (CR) and the average variance extracted (AVE). At CR $\geq 0.7$ and $A V E \geq 0.5$, convergent validity can be established. Referring to Table 4, the CR values for all constructs exceed the criterion of 0.70 , and the AVE values are above the criterion of 0.50 , establishing convergent validity [25]. 
Table 3. Confirmatory factor analysis (each item was measured with a 5-point Likert type scale).

\begin{tabular}{ccccccccc}
\hline Item & EE & SUB & BTC & SI & BOC & AT & FC & PE \\
\hline PE1 & -0.100 & 0.069 & 0.244 & 0.119 & 0.128 & 0.098 & 0.058 & 0.774 \\
PE 2 & 0.398 & -0.087 & 0.140 & 0.141 & -0.068 & -0.295 & -0.063 & 0.636 \\
PE 3 & 0.167 & 0.052 & 0.107 & -0.071 & 0.167 & 0.093 & 0.277 & 0.763 \\
EE1 & 0.738 & 0.030 & 0.163 & -00.311 & -0.199 & -0.129 & 0.188 & 0.158 \\
EE2 & 0.812 & 0.010 & 0.168 & -0.069 & 0.079 & -0.132 & 0.134 & 0.072 \\
EE 3 & 0.854 & -0.081 & 0.087 & 0.091 & -0.043 & -0.231 & -0.009 & 0.021 \\
SI1 & 0.116 & 0.085 & 0.048 & 0.768 & 0.007 & -0.083 & -0.106 & 0.146 \\
SI 2 & -0.159 & 0.010 & 0.030 & 0.891 & -0.041 & 0.135 & -0.024 & 0.030 \\
SI 3 & -0.091 & -0.029 & 0.119 & 0.891 & 0.120 & -0.062 & -0.025 & -0.048 \\
FC1 & -0.082 & 0.027 & 0.474 & -0.005 & 0.191 & 0.161 & 0.649 & 0.016 \\
FC2 & 0.131 & 0.098 & 0.170 & -0.224 & -0.181 & -0.058 & 0.758 & 0.197 \\
FC3 & 0.153 & -0.033 & -0.003 & 0.003 & 0.203 & 0.049 & 0.787 & 0.062 \\
BTC1 & 0.110 & 0.005 & 0.825 & 0.063 & 0.131 & -0.027 & 0.032 & 0.228 \\
BTC 2 & 0.289 & -0.004 & 0.824 & 0.124 & 0.143 & 0.051 & 0.115 & 0.135 \\
BTC 3 & 0.119 & 0.071 & 0.640 & 0.061 & 0.189 & 0.236 & 0.245 & 0.123 \\
BOC1 & 0.179 & 0.127 & 0.175 & 0.018 & 0.788 & 0.048 & 0.130 & 0.096 \\
BOC2 & -0.193 & 0.258 & 0.272 & -0.081 & 0.714 & 0.164 & 0.115 & 0.111 \\
BOC3 & -0.159 & 0.139 & 0.109 & 0.160 & 0.816 & 0.282 & -0.022 & 0.075 \\
AT1 & -0.171 & 0.117 & 0.018 & -0.019 & 0.165 & 0.811 & -0.025 & 0.201 \\
AT2 & -0.107 & 0.133 & 0.386 & -0.041 & 0.160 & 0.682 & -0.026 & -0.089 \\
AT3 & -0.218 & 0.047 & -0.005 & 0.038 & 0.103 & 0.821 & 0.145 & -0.080 \\
SUB1 & -0.147 & 0.826 & 0.051 & 0.081 & 0.312 & 0.076 & 0.011 & 0.015 \\
SUB2 & 0.039 & 0.915 & 0.040 & 0.074 & 0.038 & 0.077 & 0.022 & -0.002 \\
SUB3 & 0.027 & 0.904 & -0.013 & -0.075 & 0.102 & 0.099 & 0.029 & 0.053 \\
\hline
\end{tabular}

PE: performance expectancy; EE: effort expectancy; SI: social influence; FC: facilitating conditions; BTC: blockchain technological context; BOC: blockchain organizational context; AT: attitude; SUB: sustainable usage intention of blockchain. The shaded numbers $\geq 0.5$ (factors loadings).

Table 4. Results of convergent validity. CR, construct reliability; AVE, average variance extracted.

\begin{tabular}{cccc}
\hline Constructs & AVE & CR & Cronbach $\alpha$ \\
\hline Performance Expectancy & 0.718 & 0.857 & 0.721 \\
Effort Expectancy & 0.760 & 0.875 & 0.776 \\
Social Influence & 0.723 & 0.859 & 0.731 \\
Facilitating Conditions & 0.811 & 0.921 & 0.829 \\
Blockchain Technological Context & 0.779 & 0.892 & 0.798 \\
Blockchain Organizational Context & 0.752 & 0.861 & 0.781 \\
Attitude & 0.712 & 0.847 & 0.755 \\
Sustainable Usage Intention of Blockchain & 0.731 & 0.862 & 0.746 \\
\hline
\end{tabular}

Discriminant validity is the extent to which one construct differs from other constructs. It is assessed by comparing the square root of the AVE of each construct to the inter-factor correlation between two constructs. If the square root of the AVE is higher than the correlation, discriminant validity is established [25]. Referring to Table 5, all square roots of AVE values are higher than the correlations of the construct values, therefore establishing discriminant validity.

The range of absolute values for the correlation coefficients does not exceed the criterion of 0.85 , indicating the absence of multicollinearity between the constructs and therefore the overall discriminant validity. As shown in Table 6, multicollinearity was further assessed using the variance inflation factor (VIF) and the tolerance (TOL). There was no issue with multicollinearity between the variables measured. In general, VIF values of $\leq 10$ and TOL values of $\geq 0.3$ indicated the absence of multicollinearity. 
Table 5. Results of discriminant validity.

\begin{tabular}{|c|c|c|c|c|c|c|c|c|}
\hline Construct & PE & EE & SI & FC & BTC & BOC & AT & IUB \\
\hline $\begin{array}{l}\text { Performance } \\
\text { Expectancy }\end{array}$ & 0.847 & & & & & & & \\
\hline Effort Expectancy & $0.371^{* *}$ & 0.872 & & & & & & \\
\hline Social Influence & $0.429 * *$ & $0.462 * *$ & 0.850 & & & & & \\
\hline Facilitating Conditions & $0.389 * *$ & $0.357 * *$ & $0.365 * *$ & 0.901 & & & & \\
\hline $\begin{array}{c}\text { Blockchain } \\
\text { Technological Context }\end{array}$ & $0.321^{* *}$ & $0.397^{* *}$ & $0.424 * *$ & $0.409 * *$ & 0.883 & & & \\
\hline $\begin{array}{c}\text { Blockchain } \\
\text { Organizational Context }\end{array}$ & $0.299 * *$ & $0.382^{* *}$ & $0.294^{* *}$ & $0.352 * *$ & $0.412 * *$ & 0.867 & & \\
\hline Attitude & $0.357^{* *}$ & $0.423^{* *}$ & $0.472 * *$ & $0.403 * *$ & $0.317^{* *}$ & $0.324^{* *}$ & 0.844 & \\
\hline $\begin{array}{l}\text { Sustainable Usage } \\
\text { Intention of } \\
\text { Blockchain }\end{array}$ & $0.331^{* *}$ & $0.375^{* *}$ & $0.295^{* *}$ & $0.387^{* *}$ & $0.383^{* *}$ & $0.336^{* *}$ & $0.392^{* *}$ & 0.855 \\
\hline
\end{tabular}

The shaded numbers in the diagonal row are square roots of the AVE. ${ }^{* *}$ Significant at $\alpha=0.01$.

Table 6. Variance inflation factor (VIF) and tolerance (TOL).

\begin{tabular}{cccccc}
\hline & Tolerance & VIF & & Tolerance & VIF \\
\hline UTAUT & 0.710 & 1.426 & TOE & 0.697 & 1.413 \\
Attitude & 0.662 & 1.781 & & \multicolumn{2}{c}{$\begin{array}{c}\text { Dependent Variable: } \\
\text { Sustainable Usage Intention of Blockchain }\end{array}$} \\
\hline
\end{tabular}

Hypothesis testing was conducted using structural equation analysis and AMOS 24. Table 7 shows the fit statistics examined in this study. The indices indicate a good fit except for CFI, supporting further analysis under the same conditions [26].

Table 7. Fit statistics used to validate the measurement model.

\begin{tabular}{|c|c|c|}
\hline \multicolumn{2}{|c|}{ Recommended Value } & Measurement Model \\
\hline \multirow{8}{*}{ Fit statistics } & $X^{2} / \mathrm{DF}(\leq 3.000)$ & 2.890 \\
\hline & GFI $(\geq 0.900)$ & 0.913 \\
\hline & $\operatorname{RMSR}(\leq 0.050)$ & 0.042 \\
\hline & RMSEA $(\leq 0.080)$ & 0.061 \\
\hline & AGFI $(\geq 0.800)$ & 0.817 \\
\hline & CFI $(\geq 0.900)$ & 0.881 \\
\hline & TLI $(\geq 0.900)$ & 0.924 \\
\hline & PGFI $(\geq 0.600)$ & 0.619 \\
\hline
\end{tabular}

\section{Model Structure}

As illustrated in Figure 5, the UTAUT model characteristics were analyzed in terms of performance expectancy, effort expectancy, social influence, and facilitating conditions; that is, the UTAUT was decomposed into these subconstructs so it could be measured.

For $\mathrm{H} 1$, the path coefficient between the UTAUT constructs and attitude toward the adoption of blockchain was statistically significant $(\gamma=0.27, \mathrm{t}=9.24)$. When the model was validated using first-order constructs for in-depth structural analysis, the UTAUT constructs had significant effects on attitude. For $\mathrm{H} 2$, the path coefficient between the UTAUT constructs and intention to adopt blockchain was statistically significant $(\gamma=0.24, \mathrm{t}=7.98)$. The first-order factor model also confirmed the significant effects of UTAUT constructs on the sustainable usage intention of blockchain. 


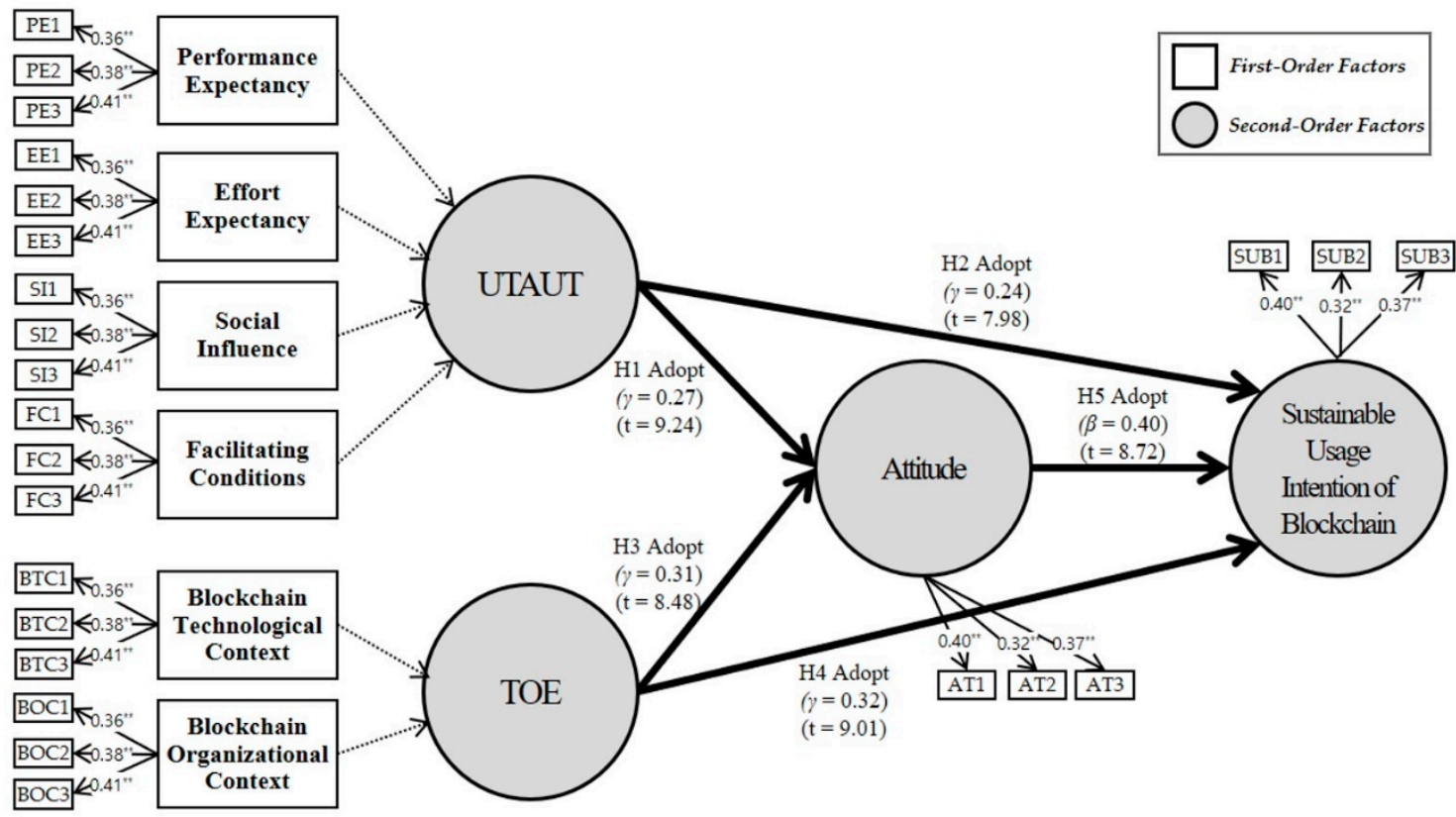

Figure 5. Results of hypothesis testing. Note: ${ }^{* *}$ significant at $\alpha=0.01$.

This finding is consistent with previous studies reporting the reciprocal relationship between UTAUT-based factors and IS attitude as well as the use intention [2,14]. Hence, UTAUT constructs, as independent variables, had strong explanatory power and positive effects on the dependent variable.

As illustrated in Figure 5, the TOE model characteristics were analyzed in terms of the technological and the organizational contexts. In other words, the TOE was decomposed into these subconstructs so it could be measured.

For $\mathrm{H} 3$, the path coefficient between the TOE constructs and attitude was statistically significant $(\gamma=0.31, t=8.48)$. The first-order factor model also confirmed the significant effects of TOE constructs on attitude. For H4, the path coefficient between the TOE constructs and the intention to adopt blockchain was statistically significant $(\gamma=0.32, t=9.01)$. When first-order constructs were used in the model for in-depth structural analysis, the TOE constructs exerted significant effects on the sustainable usage intention of blockchain.

This result is consistent with previous studies reporting the reciprocal relationship between TOE-based factors, IS attitude, and sustainable usage intention of blockchain $[18,19]$. Taken together, these findings suggest that the successful adoption of blockchain is influenced by a firm's level of technological capability and organization-wide support.

For $\mathrm{H} 5$, the path coefficient between attitude and sustainable usage intention of blockchain was statistically significant $(\beta=0.40, t=8.72)$. The first-order factor model also confirmed the significant effects of attitude on the sustainable usage intention of blockchain. This result is in agreement with previous studies suggesting the relationship between attitude and the sustainable usage intention of blockchain. Thus, attitude was found to be a positive antecedent of the sustainable usage intention of blockchain $[13,14]$.

Further information on the study results and the direct and indirect effects of independent variables are presented in Table 8 below. 
Table 8. Coefficients of direct, indirect, and total effects.

\begin{tabular}{|c|c|c|c|}
\hline & & Attitude & $\begin{array}{l}\text { Sustainable Usage } \\
\text { Intention of Blockchain }\end{array}$ \\
\hline \multirow{3}{*}{ UTAUT } & Direct Effect & $0.27^{* *}$ & $0.24^{* *}$ \\
\hline & Indirect Effect & - & $0.12^{* *}$ \\
\hline & Total Effect & $0.27^{* *}$ & $0.36^{* *}$ \\
\hline \multirow{3}{*}{ TOE } & Direct Effect & $0.31^{* *}$ & $0.32 * *$ \\
\hline & Indirect Effect & - & 0.09 * \\
\hline & Total Effect & $0.31 * *$ & $0.41^{* *}$ \\
\hline \multirow{3}{*}{ Attitude } & Direct Effect & & $0.40 * *$ \\
\hline & Indirect Effect & & - \\
\hline & Total Effect & & $0.40^{* *}$ \\
\hline
\end{tabular}

\section{Conclusions}

\subsection{Result}

This study empirically analyzed the factors that affect the intention to adopt blockchain in the logistics industry. Specifically, we identified the factors influencing the adoption of blockchain in the logistics industry using UTAUT and TOE frameworks and examined the effects of the reciprocal causal relationship between these factors, which were identified in terms of the intention to adopt blockchain. Furthermore, the concept of blockchain was defined, and blockchain logistics applications were identified through a literature review. To achieve the objectives of the study, a research framework was developed based on UTAUT and TOE frameworks. A questionnaire survey was used to collect opinions from executives and employees involved in logistics services, regardless of the sector. The collected data were analyzed using AMOS 24.0. Hypotheses were tested, and the results were discussed.

The results of this study are briefly discussed below and compared with previous research. Finally, the significance and the implications of these findings are described.

The findings of this study are summarized as follows. First, the UTAUT model characteristics were analyzed in terms of performance expectancy, effort expectancy, social influence, and facilitating conditions; that is, the UTAUT model was measured using these variables as subconstructs. Those UTAUT constructs exerted significant effects on attitude and sustainable usage intention of blockchain. In the validated model using first-order constructs for in-depth structural analysis, UTAUT constructs showed significant influence on attitude and the sustainable usage intention of blockchain. This result is consistent with the findings of Zakky and Teguh (2018) [2] and Queiroz et al. (2020) [14]. Hence, UTAUT constructs as independent variables had strong explanatory power and a positive effect on the dependent variable.

Second, the TOE model characteristics were analyzed in terms of technological and organizational contexts; that is, the TOE was measured using these variables as subconstructs. The analysis revealed that these TOE constructs exerted significant influence on attitude and the sustainable usage intention of blockchain. The first-order factor model also confirmed the significant influence of TOE constructs on attitude and the sustainable usage intention of blockchain. This result is consistent with the findings of Chan and Chong (2013) [18] and Lian et al. (2014) [19]. The results suggest that the successful adoption of blockchain is influenced by a firm's level of technological capability and organization-wide support.

Third, this study identified a causal relationship between attitude and use intention in relation to the adoption of blockchain. In further in-depth analysis using first-order constructs in the model, attitude had a significant influence on the intention to adopt blockchain. This result is consistent with the findings of Venkatesh et al. (2003) [13] and Queiroz et al. (2020) [14]. Thus, attitude was found to be a positive antecedent of the sustainable usage intention of blockchain. 


\subsection{Implication and Limitation}

This study provides the following theoretical and practical implications. First, this study provides useful information for developing strategies for expanding BT applications and for extending previous theory. Recently, the use of BT has stirred controversy in the wake of losses from speculative investment in cryptocurrencies such as Bitcoin, from illegal transactions, and from slow transaction flows due to low capacity. However, there is a growing consensus that BT will become a necessity for future economic and social development. Hence, the effort to widen the range of BT applications by influencing organizational intention to adopt BT is necessary at the government level. This study serves as a basis for future theoretical studies, including those related to government- or enterprise-led strategies for BT applications or for the creation of BT adoption models.

Second, this study utilized UTAUT and TOE frameworks. Using only the UTAUT model did not seem to be sufficient to achieve the objectives of this study. Therefore, we integrated the TOE framework as well and defined the technological and the organizational contexts as the model's constructs. Thus, the existing theoretical models were modified to create a research framework, which was then empirically tested. The model developed in this study will be useful when designing future studies.

Third, empirical research on the BT acceptance model is still in its early stages from an academic standpoint. This study also suggests that the following issues are worth investigating further in future research. Amongst opinion variables collected from the experts involved in logistics services, there were some that had a significant impact on the intention to adopt BT directly. It was also found that the intention to adopt BT was increased when the technology was expected to help employees work smarter and the logistics industry to become more efficient. This finding suggests that a specific and detailed introduction into the possible benefits of BT would facilitate its adoption into logistics companies.

Fourth, strategies for industrial convergence and fundamental infrastructure are also necessary. BT is poised to thrive through convergence. It can be integrated with logistics and distribution, public healthcare, media, finance, and public sectors and requires effective infrastructure to drive innovation. In particular, BT will provide complete solutions for payment practices performed in relation to electronic money, promissory notes, securities, insurance, and funds and will improve the efficiency in the entire process using its distributed ledger system. To boost BT adoption in these areas, adequate infrastructure is essential.

Despite the aforementioned theoretical and practical contributions to the literature, this study has several limitations with respect to the research content and methodology.

First, as blockchain's adoption is in its early stages, the respondents' lack of understanding on how it works may hinder generalizing the survey results. If future studies can undertake surveys based on a better understanding of the respondents' knowledge and awareness levels on blockchain, more generalized conclusions may be derived. In addition, studies that are complementary with each other may be called for in the future.

Second, the small sample size in the questionnaire survey also poses a limitation in terms of generalizing the results. Although the sample size did not compromise the quantitative analysis, it may be a problem when interpreting and generalizing the results. Large-scale studies are, therefore, recommended in the future.

Third, a cross-sectional study was conducted for empirical analysis. However, to determine the causal relationship between the variables more accurately, a longitudinal study across different time points would be a better choice. Future studies can be conducted through time-dependent data collection and analysis to determine the causal relationship between variables in a more accurate manner.

Funding: This research received no external funding.

Conflicts of Interest: This manuscript has not been published or presented elsewhere in part or in entirety and is not under consideration by another journal. I provided informed consent and the study design was approved by the appropriate ethics review board. I have read and understood the Sustainability's policies, and we believe that neither the manuscript nor the study violates any of these policies. There are no conflict of interest to declare. 


\section{References}

1. Mao, D.; Wang, F.; Hao, Z.; Li, H. Credit Evaluation System based on Blockchain for Multiple Stakeholders in the Food Supply Chain. Int. J. Environ. Res. Public Health 2018, 15, 1627. [CrossRef]

2. Zakky, Z.; Teguh, W. Promoting the Use of Social Commerce on SME in the Context of Logistics: UTAUT Model Examination. LOGI Sci. J. Transp. Logist. 2018, 9, 73-82. [CrossRef]

3. Cheng, Y.; Kuang, Y.; Shi, X.; Dong, C. Sustainable Investment in a Supply Chain in the Big Data Era: An Information Updating Approach. Sustainability 2018, 10, 403. [CrossRef]

4. Choi, D.; Chung, C.Y.; Seyha, T.; Young, J. Factors Affecting Organizations' Resistance to the Adoption of Blockchain Technology in Supply Networks. Sustainability 2020, 12, 8882. [CrossRef]

5. Zhang, A.; Lin, X. Towards Secure and Privacy-Preserving Data Sharing in e-health Systems via Consortium Blockchain. J. Med. Syst. 2018, 42, 140. [CrossRef] [PubMed]

6. Verhoeven, P.; Sinn, F.; Herden, T.T. Examples from Blockchain Implementations in Logistics and Supply Chain Management: Exploring the Mindful Use of a New Technology. Logistics 2018, 2, 20. [CrossRef]

7. Hao, Z.; Mao, D.; Zhang, B.; Zuo, M.; Zhao, Z. A Novel Visual Analysis Method of Food Safety Risk Traceability Based on Blockchain. Int. J. Environ. Res. Public Health 2020, 17, 2300. [CrossRef]

8. Bublitz, F.M.; Oetomo, A.; Sahu, K.S.; Kuang, A.; Fadrique, L.X.; Velmovitsky, P.E.; Morita, P.P. Disruptive Technologies for Environment and Health Research: An Overview of Artificial Intelligence, Blockchain, and Internet of Things. Int. J. Environ. Res. Public Health 2019, 16, 3847. [CrossRef]

9. Queiroz, M.M.; Telles, R.; Bonilla, S.H. Blockchain and Supply Chain Management Integration: A Systematic Review of the Literature. Supply Chain Manag. 2019, 25, 241-254. [CrossRef]

10. Treiblmaier, H. The Impact of the Blockchain on the Supply Chain: A Theory-based Research Framework and a Call for Action. Supply Chain Manag. 2018, 23, 545-559. [CrossRef]

11. Tijan, E.; Aksentijević, S.; Ivanić, K.; Jardas, M. Blockchain Technology Implementation in Logistics. Sustainability 2019, 11, 1185. [CrossRef]

12. Pournader, M.; Shi, Y.; Seuring, S.; Koh, S.L. Blockchain Applications in Supply Chains, Transport and Logistics: A Systematic Review of the Literature. Int. J. Prod. Res. 2020, 58, 2063-2081. [CrossRef]

13. Venkatesh, V.; Morris, M.G.; Davis, G.B.; Davis, F.D. User Acceptance of Information Technology: Toward a Unified View. Manag. Inf. Syst. Q. 2003, 27, 425-478. [CrossRef]

14. Queiroz, M.M.; Fosso Wamba, S.; De Bourmont, M.; Telles, R. Blockchain Adoption in Operations and Supply Chain Management: Empirical Evidence from an Emerging Economy. Int. J. Prod. Res. 2020. [CrossRef]

15. Chan, F.T.; Chong, A.Y.L.; Zhou, L. An Empirical Investigation of Factors Affecting E-Collaboration Diffusion in SMEs. Int. J. Prod. Econ. 2012, 138, 329-344. [CrossRef]

16. Dulle, F.W.; Minishi-Majanja, M.K. The Suitability of the Unified Theory of Acceptance and Use of Technology (UTAUT) Model in Open Access Adoption Studies. Inf. Dev. 2011, 27, 32-45. [CrossRef]

17. Tornatzky, L.G.; Fleischer, M.; Chakrabarti, A.K. Processes of Technological Innovation; Lexington Books: Washington, DC, USA, 1990; ISBN-13 978-0669203486.

18. Chan, F.T.; Chong, A.Y.L. Determinants of Mobile Supply Chain Management System Diffusion: A Structural Equation Analysis of Manufacturing Firms. Int. J. Prod. Res. 2013, 51, 1196-1213. [CrossRef]

19. Lian, J.W.; Yen, D.C.; Wang, Y.T. An Exploratory Study to understand the Critical Factors Affecting the Decision to adopt Cloud Computing in Taiwan Hospital. Int. J. Inf. Manag. 2014, 34, 28-36. [CrossRef]

20. Oliveira, T.; Thomas, M.; Espadanal, M. Assessing the Determinants of Cloud Computing Adoption: An Analysis of the Manufacturing and Services Sectors. Inf. Manag. 2014, 51, 497-510. [CrossRef]

21. Crosby, M.; Pattanayak, P.; Verma, S.; Kalyanaraman, V. Blockchain Technology: Beyond Bitcoin. Appl. Innov. 2016, 1, 6-10.

22. Wang, H.; Chen, K.; Xu, D. A Maturity Model for Blockchain Adoption. Financ. Innov. 2016, 2, 12. [CrossRef]

23. Sun, S.; Cegielski, C.G.; Jia, L.; Hall, D.J. Understanding the Factors Affecting the Organizational Adoption of Bigdata. J. Comput. Inf. Syst. 2018, 58, 193-203. [CrossRef]

24. Chen, D.Q.; Preston, D.S.; Swink, M. How the Use of Bigdata Analytics affects Value Creation in Supply Chain Management. J. Comput. Inf. Syst. 2015, 32, 4-39. [CrossRef] 
25. Hair, J.F.; Black, W.C.; Babin, B.J.; Anderson, R.E.; Tatham, R.L. Multivariate Data Analysis, 6th ed.; Pearson Education: Upper Saddle River, NJ, USA, 2006; ISBN-13 978-0130329295.

26. Gallagher, D.; Ting, L.; Palmer, A. A Journey into the unknown; Taking the Fear out of Structural Equation Modeling with AMOS for the First-Time User. Mark. Rev. 2008, 8, 255-275. [CrossRef]

Publisher's Note: MDPI stays neutral with regard to jurisdictional claims in published maps and institutional affiliations.

(C) 2020 by the author. Licensee MDPI, Basel, Switzerland. This article is an open access article distributed under the terms and conditions of the Creative Commons Attribution (CC BY) license (http://creativecommons.org/licenses/by/4.0/). 